\title{
A Case Study of Teacher's Questioning and Students' Critical Thinking in College EFL Reading Classroom
}

\author{
Ping Shen (Corresponding author) \\ The Institute of Foreign Language, Kaili University \\ No. 3 Kai Yuan Road, Kaili 556011, Guizhou, China \\ E-mail: amanda198433@yahoo.com
}

Butsakorn Yodkhumlue

School of English, The Institute of Social Technology, Suranaree University of Technology

111 University Avenue, Muang District, Nakhon Ratchasima 30000, Thailand

E-mail: butsakorn@ @otmail.com

Received: October 24, 2011

Accepted: November 27, $2011 \quad$ Published: February 1, 2012

doi:10.5539/ijel.v2n1p199

URL: http://dx.doi.org/10.5539/ijel.v2n1p199

\begin{abstract}
The present case study mainly focused on the effects of a teacher's questions on the development of students' critical thinking. The purpose was to investigate whether teacher's questions could facilitate students' critical thinking which required students to manipulate knowledge instead of direct recalling. Classroom observation and interview were employed in the study. A teacher's questioning behavior was observed and 17 students were interviewed. The results showed the teacher asked more lower-cognitive questions (79.2\%) than higher ones $(20.8 \%)$. Based on the theory of the cognitive domain, results revealed that excessive use of lower-cognitive questions could not facilitate the development of students' critical thinking. Additionally, the misuse of higher-cognitive questions by the teacher was also identified.
\end{abstract}

Keywords: Teacher's questioning, Critical thinking, The cognitive domain, Bloom's taxonomy, Lower-cognitive question, Higher-cognitive question

\section{Introduction}

In the classroom, teacher's questioning plays a very important role to initiate classroom talk. It is evident that a question can stimulate students' motivation, focus their attention, help students learn and think better, and also help the teacher know how well a student's learning is (Dillon, 1988). Therefore the investigation on teacher's questioning behavior has been an important issue in the language classroom. There have been many research studies which revealed teachers preferred to ask plenty of questions with different purposes in the classroom (Long \& Sato, 1983; White \& Lightbown, 1984; Roth, 1996; Almeida, 2010). Obviously, during the process of teaching and learning, teacher's questioning plays a crucial role in the classroom. Question-and-answer activity is viewed as the most common form of communication between students and teachers in the classroom.

In previous studies, the majority of researchers explored teachers' questioning behavior in the classroom and presented valuable results for language teaching and learning (Zhou \& Zhou, 2002; Hu, 2004; David, 2007). However, those studies mainly focused on the influence of teachers' questions on classroom interaction or learners' oral output. Few research studies have examined the influence of teachers' questioning and students' critical thinking (CT) in the Chinese context. Recently, developing students' higher-order thinking, in particular CT, has become a hot issue in the field of language education. Since the 1960s some American educators noticed the importance of CT; more and more educators from all over the world have regarded it as a necessary part of learning. It is known that CT is an important ability which can contribute to the development of the human being. It can help learners analyze, evaluate, and construct their thinking (Glaser, 1941). However, in China, CT was ignored by educators and teachers unconsciously for several years due to the Chinese ancient culture. Teachers were viewed as the authority and students had to learn what they were taught passively, which made them get 
used to being submissive learners. Furthermore, teacher-fronted instruction has dominated Chinese language classroom for many years. Students were viewed as an empty vessel merely waiting for knowledge from teachers. Fortunately, with the development of Chinese education, the focus on facilitating students' CT has been proposed by more and more Chinese educators. According to the Curriculum Requirements for College English Majors (CRCEM), which was published by the Ministry of Education of the People's Republic of China (MOE) in 2000, current English teachers are required to cultivate students' competences in learning, applying, analyzing problems and CT (MOE, 2000). Unquestionably, given the importance of CT, it is clear that cultivating learners' CT has become an imperative issue in Chinese college education.

Therefore, it is worthwhile doing investigation on the real situation in the Chinese classroom, namely, whether students' CT can get improvement with the help of teachers. Considering the functions of teachers' questions and the importance of $\mathrm{CT}$, the researcher conducted the study to investigate the relationship between teacher's questions and students' CT. This is because one way to engage language learners in higher-order thinking, namely, CT, is to ask them higher-cognitive questions (HCQ) (Nagappan, 2001). Thus, the first purpose of the present case study was to investigate the common features of teacher' questions in Chinese college EFL reading classroom so that information about teacher's questioning behavior could be obtained. The second purpose was to ascertain whether teacher's questions could facilitate learners' CT related to the four higher-order thinking levels under investigation, so that the current situation of cultivating students' CT through teacher's questioning in the classroom could be investigated, and therefore improvement could be suggested. Based on the purposes of the study listed above, this study was driven by the following research questions:

1) What are the common features of questions asked by the teacher in college EFL reading classroom under investigation?

2) Can the teacher's questions facilitate learners' critical thinking under the investigation? Why or Why not?

\section{Methodology}

\subsection{Research Instruments}

Classroom observation can provide the opportunity to record information as it occurs in a setting and it is fruitful and workable to reveal the classroom teaching and learning strategies (Creswell, 2005). Therefore, in the study, classroom observation was employed as the main instrument to collect the data concerning teacher's questioning behavior. Additionally, semi-structured interview was also used for collecting the data from students. Since teacher's questions are proposed for students, it is worthwhile analyzing teacher's questions in terms of students' perceptions; furthermore, a face-to-face interview offers the researchers more opportunities to ask participants directly about what is going on (Robson, 1993). Thus, the purpose of the interview was to elicit information from students on their attitudes towards teacher's questions, particularly focusing on the improvement of students' CT. The interview questions were designed by the researcher based on four higher-order thinking levels of the cognitive domain. The interview included five question items. The first four items were mainly related to students' perceptions on their improvement of CT with the help of teacher's HCQ and the last one focused on the students' overviews on teacher's questions. The validity of interview questions was checked by using Item-Objective Congruence Index (IOC) which is a validity method for the relevancy of the content and the purpose of the interview. The result of current interview questions is 0.94 . According to Pinyoanantapongs (1974), the acceptable value should be equal to or greater than 0.5 . That is to say, all the interview questions were relevant to the present study.

\subsection{Data Collection}

The study was conducted in Kaili University (KU) which is a newly founded comprehensive university located in the southwest of China, a remote mountainous area. There are 13 institutes in KU, including the Institute of Foreign Language. An English reading teacher and her students majoring in English $(\mathrm{N}=40)$ were included in the case study. The classroom observation was conducted around three months, totally 20 hours. Before observing, the teacher was told that the observations were merely for learning the normality rather than for evaluation in order to avoid any adjustment from her. During the observation, only the questions related to the teaching content were collected. Audio-taping and note-taking both were used to collect teacher's questions. In terms of semi-structured interview, according to the criterion for determining a representative interview sample, a total of 17 students out of 40 were randomly selected from the class to be interviewees. All the information from informants was also recorded by using both note-taking and audio-recording technique, transcribed and translated into English for data analysis. 


\subsection{Data Analysis}

\subsubsection{Analytical Framework}

The cognitive domain of Bloom's taxonomy was chosen as the analytical framework in the study. The reasons for choosing it as the framework are listed in the following. Firstly, the cognitive domain of Bloom's taxonomy is deemed as the best-known and most widely used paradigm in education to categorize and analyze the types of questions (Bernadowski, 2006). Secondly, as for the purpose of the present study, it aimed at exploring the influence of teacher's questions on students' CT. According to Jacobsen, Eggen and Kauchak (1999), with regard to Bloom's taxonomy, the domain which has the most impact on the CT issue is the cognitive domain. Therefore, undoubtedly, the cognitive domain is relatively appropriate and practical for the purposes of the current study.

Bloom's taxonomy was first proposed in 1956 at the University of Chicago by Bloom and his colleagues. Arends (1991) claimed that Bloom's taxonomy has been widely used as an aid in planning instructional goals as well as for other aspects of teaching; for instance, it can be used to assist in test construction and also to choose a questioning strategy. The cognitive domain involves knowledge and the development of intellectual skills, which includes the recall or recognition of specific facts, procedural patterns, and concepts that serve in the development of intellectual abilities and skills (Bloom, Englehart, Furst, Will, \& Krathwohl, 1956). It contains six levels: knowledge, comprehension, application, analysis, synthesis, and evaluation, which are often used to categorize teachers' questions. The first two levels, knowledge and comprehension, are regarded as lower-cognitive levels, while the last four levels are classified as higher-cognitive levels (Bloom et al., 1956; Wilen, 1991; McNeil, 2010). Questions belonging to lower-cognitive levels are likely to require students to simply recall the prescribed data from memory, concentrating on factual information whereas ones belonging to higher-cognitive levels require students to be engaged in higher-order thinking, especially CT, for instance problem solving, analyzing, creating or evaluating information (Gall, 1970; Bernadowski,2006). Bloom also defined the key words and related questions of each level in the cognitive domain, which were utilized as the principal factors in determining the classification of teacher's questions in the present study.

\subsubsection{Analysis Procedures}

After collecting the data from classroom observation, the audio-recorded data related to teacher's questions were transcribed verbatim. As a result, 289 content-related questions were collected. To guarantee the reliability of question categorization, the inter-rater reliability (measured by percent agreement) in question categorization was checked. Two raters, using the cognitive domain of Bloom's taxonomy, independently categorized questions asked by the teacher. Then the Holsti's coefficient of reliability (C.R.) was employed to calculate percent agreement. Of 289 questions, two independent raters achieved an $82 \%$ inter-rater reliability in question categorization. The result of 0.82 is greater than 0.75 (C.R. > 0.75), which means the categorization is excellent agreement and reliable (Capozzoli, McSweeney \& Sinha, 1999). As for those questions which did not achieve agreement, two raters discussed and then modified decisions based on the theory of the cognitive domain.

As aforementioned, the semi-structured interview aimed at investigating students' perceptions on teachers' questions, mainly focusing on HCQ and learners' CT. The data collected were analyzed in a qualitative way to describe why and what attitudes of students were towards the teacher's HCQ. In addition, the data from interview could also be the support for the data from classroom observation.

\section{Results and Discussion}

\subsection{Common Features of Teacher's Questions}

To answer research question 1, data from classroom observation and semi-structured interview were used. After observing in the classroom, the researcher found the teacher asked totally 289 content-related questions including both lower-cognitive and higher-cognitive levels as well. The samples of questions asked by the teacher are provided in Table 1.

From Table 1, as we can see, the teacher asked knowledge, comprehension, application, analysis, synthesis, and evaluation questions respectively in the classes. In other words, both lower-cognitive questions (LCQ) and HCQ were raised by the teacher.

In terms of the frequency of each type of questions, as illustrated in Table 2, obviously, the number of LCQ was much higher than the one of HCQ. That is to say, during 20-hour classes, the teacher asked more LCQ (79.2\%), in particular knowledge questions (66.1\%), than HCQ (20.8\%).

As for interview which could avoid the subjectivity and unilateralness of only using classroom observation as the one instrument, the last interview question item was used to explore the students' overviews on teacher's 
questions. From the records of interview, the interviewees indicated the types of questions asked by the teacher which are summarized as follows.

1) Questions related to factual or specific information in articles

The interviewees indicated that the teacher preferred to ask plenty of such kind of questions to check their understanding. For example, "What happened in the article?". Based on the research framework, those questions belonged to LCQ especially knowledge questions, because they helped student fulfill the learning requirements at the lower-cognitive level for reading course, that is, grasping the main contents of materials.

2) Questions related to previous knowledge

The interviewees also revealed that a large number of these questions were proposed by the teacher at the beginning of classes. Questions related to previous knowledge also belonged to LCQ since they required students to recall prescribed knowledge directly.

3) Questions related to evaluating or analyzing

From the views of students, the teacher proposed a few questions that had them be engaged in evaluating or analyzing, through which they could express their different opinions on the information from articles. According to the theory of the cognitive domain, those questions were classified as HCQ in that they required the process of higher-order thinking.

To sum up, therefore, unquestionably, in terms of students' perceptions, the teacher asked both LCQ and HCQ in the classes; moreover she spent more time asking substantive LCQ. These results could be the support of the data from classroom observation which also indicated both LCQ and HCQ were asked in the classes and the number of LCQ was much higher than that of HCQ. Additionally, the results are in line with those in studies of Sellappah, Hussey, Blackmore, and McMurray (1998), Ho (2005), and Almeida (2010) in that all of them also found teachers under observations were always inclined to ask more LCQ than HCQ in the classes.

\subsection{Effects of Teacher's Questions on the Development of Students' CT}

This section is related to the second research question. To answer researcher question 2, the data from classroom observation and interview as well were employed. The researcher analyzed the influence of teacher's questions on students' CT from two aspects: teacher's LCQ and HCQ.

\subsubsection{Teacher's LCQ and Students' CT}

The result of classroom observation showed the teacher asked plenty of LCQ (79.2\%) in the classroom. In light of the theory of the cognitive domain, LCQ are likely to require students to simply recall the prescribed data from memory, concentrating on factual information, and also to grasp the meanings of materials (Bloom et al., 1956; Brualdi, 1998; Bernadowski, 2006). Furthermore, as for LCQ asked by the teacher, from the records of observations, all of them were related to vocabulary, sentence structures and specific content of texts, which always required students to locate answers from memory or textbooks directly, instead of the process of higher-order thinking. Therefore, it can be concluded that excessive use of these questions could not be beneficial to the development of students' CT. This finding is in correspondence with that of Sellappah et al. (1998) which also reported that the use of LCQ could not contribute to the development of students' CT since they merely required students' recalling the knowledge directly rather than processing or manipulating knowledge. Nevertheless, although LCQ are not beneficial to the development of students' CT, this does not mean LCQ are purposeless. Actually, they are still necessary to be asked in the class because they can help students achieve the learning requirements at the lowest level of understanding.

\subsubsection{Teacher's HCQ and Students' CT}

In terms of the quantity of teacher's HCQ

In the classes, according to the data from classroom observation, the teacher also asked a few HCQ (20.8\%). The records of interview revealed the informants' views on teacher's questions, mainly focusing on application, analysis, synthesis, and evaluation questions. All of these questions were related to CT skills. The result of the interview is shown in Table 3.

As Table 3 indicated, apparently, excepting indecisiveness from a few interviewees, the majority of them held the same attitude that they did not get any improvement on abilities of problem solving, organizational structure analyzing, imagination, creation, and judgment which were related to CT skills. To illustrate:

\section{Excerpt 1}

“...sometimes she also uses a few questions to guide us learn articles step by step. But I think they 
are not enough to improve my ability of analysis. So I think if possible, I hope the teacher can pay more attention to this ability and ask many questions which can help us improve it. "

(Student 1)

\section{Excerpt 2}

“...I think in the classroom the teacher asks such questions related to evaluation, but not often, for example, what is your attitude towards the writer's main claim? ...But because of the limited questions, it is difficult to see my improvement on this ability ... ".

(Student 2)

\section{Excerpt 3}

"...analyzing the organizational structures is not an easy job for me. But in the class, the teacher just asks a few questions about it. I think it is not enough to improve this ability. So I hope she can spend more time asking such questions to improve us... "

(Student 5)

As illustrated in examples, students thought that a few HCQ provided by the teacher were too limited to improve their abilities of CT. This comment can get the support from studies of Dong (2006), and Almeida (2010) which indicated that insufficient higher-order thinking instructions may limit the development of students' higher-order thinking. The results in the study of Sellappah et al. (1998) also implied that the limited use of HCQ by teachers may limit the extent to develop students' CT. Hence, undoubtedly, it can conclude that the limited teacher's HCQ could not facilitate students' CT. In terms of the quality of teacher's HCQ

This part mainly analyzes the quality of teacher's HCQ which are illustrated based on the data from classroom observation and semi-structured interview. From the records of observations, the misuse of HCQ was identified. To illustrate:

\section{Excerpt 4}

T: What kind of life do you prefer "eat-to-live" or "live-to-eat"?

S1: Eat-to-live.

T: Eat-to-live. En... good. Do you know what the meanings of "eat-to-live" and "live-to-eat" are?

Ss: ...... (student translated it into Chinese)

The Excerpt 4 derives from classroom observation, which presents a question-and-answer chain between the teacher and students. Based on the analytical framework, the first question of teacher (What kind of life do you prefer "eat-to-live" or "live-to-eat"?) was categorized as evaluation question since it required students to judge these two types of lives and express their opinions. Sellappah et al. (1998) suggested that questions were required to be asked a logical format to facilitate a chain of reasoning so that they could prompt the development of CT., moreover, Fisher (2001) pointed out that skillful reasoning is the key element in CT. However, obviously, there was no chain of reasoning in this example. The teacher moved to another LCQ (Do you know what the meanings of "eat-to-live" and "live-to-eat" are?) instead of requiring students to justify their answers. The way that students answered the first question was similar to doing optional questions. Although this question was categorized as higher-cognitive one, its role played in the class was similar to LCQ. Therefore, it comes to a conclusion that teacher's HCQ could not facilitate students' CT under investigation. After investigating the studying and working experiences of that teacher, the reason why the teacher asked HCQ in this way may be that the teacher had never been taught how to ask HCQ. The following examples from semi-structured interview can illustrate this comment:

\section{Excerpt 5}

“...teacher sometimes asks some questions which make us predict. But I can not follow the question when she uses difficult sentences...En...if a good classmate gives the answer immediately, at this time, the teacher always praises her/him, and then move to next part...moreover, sometimes, she always speaks fast so that I can not follow..."

(Student 11)

\section{Excerpt 6}

“...in one class, the teacher asked us to evaluate author's claim. I can not remember exactly her questioned, but I did not understand her question at that time because of some unfamiliar words. 
After asking, she nominated a student to answer it, and then moved to another part after providing feedback. So, although the teacher asked us to evaluate, I don't think I get any improvement on such ability because of the way she questioned..."

(Student 15)

As mentioned in Excerpt 5 and 6, some informants indicated that sometimes they could not understand teacher's questions, especially HCQ, because of fast speaking speed of teacher's instruction and unfamiliar words in the question sentences. It is evident that the effects of those questions on students were not as satisfied as they were supposed to be. Probably, the teacher did not repeat or explain her questions because of the limited classroom time, large class size, or amount of required teaching content; however, the ultimate intention of classroom teaching activities is to reach the optimum positive effects on the learners, not merely to fulfill the content assigned to teach them. Obviously, in light of excerpts listed above, those difficult questions asked by the teacher may not make any contribution to the learners' higher-level learning. Therefore, teachers are expected to use effective questioning strategy to maximize the positive effects of questions on students' learning. Based on the teacher's performance of asking HCQ, it is suggested that language teachers need to be trained how to ask questions effectively, in particular HCQ. This finding further reinforces Gall's (1970) belief that teachers have to be taught the skill of questioning, and how to use questioning strategy effectively.

\section{Conclusion and Recommendation}

Teacher's questioning is regarded as one of the most important activities in EFL classroom. Based on the theory of the cognitive domain, the most important thing is that HCQ can promote students' higher-order thinking, that is, CT. This is because HCQ can require students to engage in independent thinking such as problem solving, analyzing and evaluating information. In the present case study, it was assumed that the teacher would ask sufficient HCQ to promote students' CT because of the curriculum requirements (CRCEM). However the findings of the study are in contrast with this assumption. The results showed that the teacher asked more LCQ related to recalling facts or grasping main contents of materials, especially knowledge, than HCQ. The results also revealed the limited use of HCQ would limit the development of students' CT. Moreover, the weakness of teacher's questioning behavior was identified. A few of HCQ from the teacher, in lacking a chain of reasoning and explicit instruction, could not prompt the development of CT either. Therefore, the case study recommends that teachers are expected to pay more attention to HCQ after asking a series of LCQ in order to provide an environment rich in opportunity for enabling CT. Additionally, teachers should be trained how to ask questions appropriately and effectively, especially HCQ.

However like other research studies so far in the field of second language acquisition, the study brought in certain limitations which should be clarified to overcome doubts about the reliability and validity of the study. Firstly, the subjects were limited to the college English teachers in China. It might not be considered as representatives of English teaching in other provinces; secondly, this study only focused on the cognitive domain in Bloom's taxonomy which is regarded as the domain that has the most impact on CT. Thus, the research did not consider using the affective and psychomotor domains to analyze teacher's questions.

Therefore, in order to increase the generalizability, a large-scale research study is recommended. More teachers from the same university or different regions in China can be involved. Additionally, it is recommended to conduct an experimental study which can demonstrate how to use questioning strategy to improve students' CT. This kind of study may not only strength the theory that teacher's HCQ can facilitate students' CT, but also further explore how to use questioning strategy to improve CT, which can provide practical and valuable information for language teaching and teacher training.

\section{References}

Almeida, P. A. (2010). Questioning patterns and teaching strategies in secondary education. Procedia Social and Behavioral Sciences, 2, 751-756. http://dx.doi.org/10.1016/j.sbspro.2010.03.096

Arends, R. I. (1991). Learning to teach. New York: McGraw-Hill, (Chapter 3).

Bernadowski, C. C. (2006). The effects of middle school social studies teachers' questioning patterns on learners' outcomes. Unpublished Doctoral Dissertation, University of Pittsburgh.

Bloom, B. S., Englehart, M. D., Furst, E. J., Will, W. A. \& Krathwohl, D. R. (1956). Taxonomy of educational objectives: The classification of educational goals, handbook I : cognitive domain. New York: David McKay.

Brualdi, A. C. (1998). Classroom questions: practice assessment research and evaluation. [Online] Available: http:// PAREonline. net (May 13, 2011) 
Capozzoli, M., McSweeney, L. \& Sinha, D. (1999). Beyond Kappa: A review of interrater agreement measures. The Canadian Journal of Statistics, 27(1), 3-23. http://dx.doi.org/10.2307/3315487

Creswell, J. W. (2005). Educational research: planning, conducting, and evaluating quantitative and qualitative research. New Jersey: Merrill Prentice Hall, (Chapter 8).

David, O. F. (2007). Teachers' questioning behavior and ESL classroom interaction pattern. Humanity and Social Science, 2(2), 127-131.

Dillon, J. T. (1988). Questioning and teaching: A manual of practice. New York: Teachers College Press, (Chapter 3).

Dong, Y. R. (2006). Learning to think in English. Educational Leadership, 64(2), 22-26.

Fisher, A. (2001). Critical thinking: an introduction. Cambridge University Press, (Chapter 2).

Gall, M. D. (1970). The use of questions in teaching. Review of Educational Research, 40(5), 707-721.

Glaser, E. M. (1941). An experiment in the development of critical thinking. Teachers' College, Columbia University, 12(3), 27-35.

Ho, D. G. E. (2005). Why do teachers ask the questions they ask? RELC, 36(3), 297-310. http://dx.doi.org/10.1177/0033688205060052

$\mathrm{Hu}, \mathrm{Q}$. (2004). A survey of the models of college English teachers' questioning. Foreign Language World, 4, 22-27.

Jacobsen, D. A., Eggen, P. \& Kauchak, D. (1999). Methods for teaching: promoting student learning. New Jersey: Prentice Hall, (Chapter 5).

Long, M. H. \& Sato, C. J. (1983). Classroom foreign talk discourse: forms and functions of teacher's questions. TESOL Quarterly, 15, 26-30.

McNeil, L. (2010). Beyond the products of higher-order questioning: How do teacher and English-language learner perceptions influence practice? TESOL, 2.74-90.

MOE. (2000). Curriculum Requirements for College English Majors. Beijing: The People's Education Press.

Nagappan, R. (2001). Language Teaching and the Enhancement of Higher-Order Thinking Skills. Singapore: SEAMEO Regional Language Center. [Online] Available: http://nsrajendran.tripod.com/Papers/RELC2000A.pdf (April 20, 2001)

Pinyoanantapongs, B. (1974). Evaluation by references criteria, concepts and methods. Fundamental Education Division. Faculty of Educational Study, Srinakharinwirot University (Ed.) Fundamental Education Division (pp: 89-299). Bangkok: ISBN: 974-275-874-3.

Robson, C. (1993). Real World Research: A Resource for Social Scientist and Practitioner-Researcher. Oxford: Blackwell Publishers, (Chapter 9).

Roth, M. W. (1996). Teacher questioning in an open-inquiry learning environment: interactions of context, content, and student Responses. Journal of Research in Science Teaching, 33(7), 710-735. http://dx.doi.org/10.1002/(SICI)1098-2736(199609)33:7<709::AID-TEA2>3.0.CO;2-R

Sellappah, S., Hussey, T., Blackmore, A. M. \& McMurray, A. (1998). The use of questioning strategies by clinical teachers. Journal of Advanced Nursing, 28(1), 142-148. http://dx.doi.org/10.1046/j.1365-2648.1998.00776.x

White, J. \& Lightbown, P. (1984). Asking and answering in ESL classes. Canadian Modern Language Review, 40(2), 228-244.

Wilen, W. W. (1991). Questioning skills, for teachers. Washington DC: National Education Association of the United States, (Chapter 2).

Zhou, X. \& Zhou, Y. (2002). A research and analysis of teacher talk in college English classrooms. Foreign Language Teaching and Research, 34(1), 66-71. 
Table 1. Samples of Questions Asked by the Teacher

\begin{tabular}{|c|l|}
\hline \multicolumn{1}{|c|}{ Types } & \multicolumn{1}{c|}{ Examples } \\
\hline Knowledge & $\begin{array}{l}\text { 1. What happened in the passage? } \\
\text { 2. What does CPU stand for? }\end{array}$ \\
\hline \multirow{2}{*}{ Comprehension } & $\begin{array}{l}\text { 1. Why did the father want Susie to follow his career? } \\
\text { 2. Please translate this paragraph. }\end{array}$ \\
\hline Application & 1. What should we do when things go bad? \\
\hline \multirow{2}{*}{ Analysis } & $\begin{array}{l}\text { 1. What is the topic of this passage? } \\
\text { 2. What kind of pattern do you think is the second paragraph? }\end{array}$ \\
\hline \multirow{2}{*}{ Synthesis } & $\begin{array}{l}\text { 1. What can you learn from the title? } \\
\text { 2. Can you predict the relationship between the father and the daughter in } \\
\text { the article? }\end{array}$ \\
\hline \multirow{2}{*}{ Evaluation } & $\begin{array}{l}\text { 1. What's your impression on all things in the articles? } \\
\text { 2. In your opinion, what kind of life can be called "good life"? }\end{array}$ \\
\hline
\end{tabular}

Table 2. Frequency of Each Type of Questions

\begin{tabular}{|c|c|c|}
\hline Levels & Types & Frequencies (\%) \\
\hline \multirow{2}{*}{ Lower-Cognitive } & Knowledge & $191(66.1)$ \\
\cline { 2 - 3 } & Comprehension & $38(13.1)$ \\
\hline \multirow{2}{*}{ Total } & & $\mathbf{2 2 9}(\mathbf{7 9 . 2})$ \\
\hline \multirow{3}{*}{ Higher-Cognitive } & Application & $11(3.8)$ \\
\cline { 2 - 3 } & Analysis & $24(8.3)$ \\
\cline { 2 - 3 } & Synthesis & $5(1.7)$ \\
\cline { 2 - 3 } & Evaluation & $20(7.0)$ \\
\hline Total & & $\mathbf{6 0}(\mathbf{2 0 . 8})$ \\
\hline Grand Total & & $\mathbf{2 8 9}$ \\
\hline
\end{tabular}

Table 3. The 17 Interviewees' Responses on Teacher's HCQ

\begin{tabular}{|c|c|c|c|c|}
\hline \multirow{2}{*}{ Interview Question Items } & \multicolumn{3}{|c|}{ Responses } & N \\
\cline { 2 - 4 } & Yes (\%) & No (\%) & Not Sure (\%) & \\
\hline $\begin{array}{c}\text { Question Item 1 } \\
\text { (related to application questions) }\end{array}$ & $0(0.0)$ & $17(100.0)$ & $0(0.0)$ & 17 \\
\hline $\begin{array}{c}\text { Question Item 2 } \\
\text { (related to analysis questions) }\end{array}$ & $0(0.0)$ & $14(82.4)$ & $3(17.6)$ & 17 \\
\hline $\begin{array}{c}\text { Question Item 3 } \\
\text { (related to synthesis questions) }\end{array}$ & $0(0.0)$ & $16(94.1)$ & $1(5.9)$ & 17 \\
\hline $\begin{array}{c}\text { Question Item 4 } \\
\text { (related to evaluation questions) }\end{array}$ & $0(0.0)$ & $15(88.2)$ & $2(11.8)$ & 17 \\
\hline
\end{tabular}

(Note: $\mathrm{N}=$ Number of the Interviewees) 